\title{
Perfect State of Cryptococcus uniguttulatus
}

\author{
K. J. KWON-CHUNG \\ Laboratory of Clinical Investigation, National Institute of Allergy and Infectious Diseases, National Institutes \\ of Health, Bethesda, Maryland 20014
}

\begin{abstract}
The sexual state of Cryptococcus uniguttulatus has been described as Filobasidium uniguttulatum in the Filobasidiaceae. The new species is characterized by slender basidia with 4 to 10 sessile reniform to oval basidiospores produced in a terminal cluster. The strains of $F$. uniguttulatum are heterothallic. The morphological and physiological characteristics of $F$. uniguttulatum are compared with those of two previously known species in the genus Filobasidium.
\end{abstract}

In 1968 Olive (11) erected a new genus, Filobasidium, to accommodate a new heterobasidiomycetous fungus which was isolated from a large plume grass. He described the fungus as Filobasidium floriforme (11), and the asexual state was later identified as Cryptococcus albidus (10). The genus Filobasidium is characterized by long slender nonseptate basidia bearing sessile basidiospores terminally. In 1972, Rodrigues de Miranda (14) described the second species in the genus as Filobasidium capsuligenum, the sexual state of Candida capsuligena (van der Walt and van Kerken) van Uden and Buckley (17). This fungus was previously classified by Fell et al. in the genus Leucosporidium (2).

During the course of phylogenetic studies with various species of Cryptococcus, heterothallism was found among the isolates of Cryptococcus uniguttulatus. This paper provides a description of the sexual state and the life cycle of $\mathrm{Cr}$. uniguttulatus.

\section{MATERIALS AND METHODS}

Isolates. The sources of three strains of $\mathrm{Cr}$. uniguttulatus, including the type culture of the species, used in this study are listed in Table 1 . Cultures were purified by obtaining single clones and maintained on malt extract agar slants at $25^{\mathrm{c}} \mathrm{C}$.

Mating. Hay infusion agar (13) and V-8 juice agar were used as standard media for mating tests. Loopfuls of yeast cells from 3-day-old cultures were mixed in pairs of all possible combinations on agar plates and incubated at $25^{\circ} \mathrm{C}$ for 1 to 2 weeks.

The tester strains $\mathrm{Cu} 1$ and $\mathrm{Cu} 2$ were also crossed with the two mating types of $F$. floriforme (ATCC 22367, ATCC 22368) and the two mating types of $F$. capsuligenum (ATCC 22179, ATCC 22180).

Genetic analysis of mating type. Ten single basidiospores were randomly isolated from the cross $\mathrm{Cu} 1 \times \mathrm{Cu} 2$ by using a deFonbrune micromanipulator. All 10 single-basidiospore cultures were backcrossed to analyze their mating types.

Nuclear staining of hyphae. A modified method of the basic fuchsine technique (4) was used to observe the dikaryon in hyphae. A 2-week-old mated culture plate was exposed to formaldehyde fumes by placing a Formalin-(saturated) soaked filter paper inside the lid and then leaving the plate inverted for $24 \mathrm{~h}$ at $25^{\circ} \mathrm{C}$. A small thin agar block containing hyphae was cut out from the plate and placed on a microscope slide with a few drops of $0.5 \%$ basic fuchsine (dissolved in $1 \mathrm{~N} \mathrm{HCl}$ ). After $5 \mathrm{~min}$ of staining, the agar block was then pressed with another slide and the slides were drawn apart to give a thin preparation. A drop of $75 \%$ alcohol was added on the thin preparation before placing a cover glass. Observation was made under a compound microscope within an hour of staining.

Physiological tests. All three original isolates and five single basidiospore isolates obtained from the cross $\mathrm{Cu} 1 \times \mathrm{Cu} 2$, two strains of $F$. capsuligenum, and two strains of $F$. floriforme were tested for the fermentation and assimilation of various sugars (see Table 4) and assimilation of nitrate and inositol by conventional methods described previously $(8,18)$. Growth at 30 and $37^{\circ} \mathrm{C}$ was also tested. Presence of urease and phenol oxidase was checked by using urea (1) and niger seed agar media (16), respectively.

\section{RESULTS}

Prior to a discussion of the life cycle of $\mathrm{Cr}$. uniguttulatus, description of the new species is presented.

Filobasidium uniguttulatum Kwon-Chung sp. nov. Basidia 4-6 $\times 30-90 \mu$ e mycelio oriunda; basidiosporae ovatae vel reniforme, 3-5 $\times 4-9 \mu$ plerumque $4-10$ in basidii apice sublatae, germinatione blastosporas producentia. Fungus heterothallicus. Status asexualis: Cryptococcus uniguttulatus. Typus cultura: ATCC $24227=$ CBS 1730 (a typus) et ATCC $32047=$ CBS 1727 ( $\alpha$ typus). Collectione American Type Culture Collection, Rockville, Md.

Fungus heterothallic; basidia hyaline, produced mostly in groups (see Fig. 12) but sometimes singly on dikaryotic hyphae with clamp connections, nonseptate, slender with globose apexes (see Fig. 10), 30 to $90 \mu \mathrm{m}$ long, 4 to $6 \mu \mathrm{m}$ wide near the base and 1.5 to $3 \mu \mathrm{m}$ wide near 
TABLE 1. Three strains of Cryptococcus uniguttulatus used

\begin{tabular}{lll}
\hline Isolate & $\begin{array}{c}\text { Origin } \\
\text { (human) }\end{array}$ & \multicolumn{1}{c}{ Source $^{a}$} \\
\hline Cu1 & Diseased nail & $\begin{array}{c}\text { ATCC 24227 }=\text { CBS 1730 } \\
\text { (Type culture) }\end{array}$ \\
Cu2 & Diseased nail & ATCC 32047 = CBS 1727 \\
Cu3 & Throat & ATCC 32048 $=$ CBS 2770 \\
\hline
\end{tabular}

a ATCC, American Type Culture Collection, Rockville, Md.; CBS, Centraalbureau voor Schimmelcultures, Delft, Netherlands.

the apex; the apex of the basidium globose, 3 to $5 \mu \mathrm{m}$ in diameter, producing 4 to 10 sessile basidiospores terminally; basidiospores smooth, ovate, or kidney shaped (see Fig. 13), 3 to 5 by 4 to $9 \mu \mathrm{m}$; basidiospores germinating on agar to produce blastospores; blastospores also produced by budding from hyphae, globose, subglobose to oval, 2.5 to $7 \mu \mathrm{m}$ in diameter, with mucoid capsule. Asexual state: Cryptococcus uniguttulatus (see Fig. 2). Type cultures: ATCC 24227 = CBS 1730 (a type) and ATCC $32047=$ CBS 1727 ( $\alpha$ type) .

Heterothallism and the genetic analysis of mating type. All three original isolates of $\mathrm{Cr}$. uniguttulatus were self-sterile and required mating with compatible isolates to produce the basidiomycetous state. Results of the crosses among the isolates are presented in Table 2. The isolate $\mathrm{Cu} 1=\mathrm{ATCC} 24227$ is designated by customary symbol $\mathbf{a}$ and isolates $\mathrm{Cu} 2$ and $\mathrm{Cu} 3$ are designated as $\alpha$. Malt extract agar, V-8 juice, and hay infusion agar (Fig. 1) supported the formation of perfect state, but hay and V-8 juice agar consistently gave better results than malt extract agar.

The results of backcrossing (Table 3 ) show that the fungus is heterothallic. Two of the single basidiospore isolates were self-fertile and their nuclear states or ploidy have not been determined.

Development of basidiomycetous state. Microscopic observations of mated cultures reveal that the sexual state is initiated by the formation of a conjugation tube. The conjugation tube measures 1 to $1.5 \mu \mathrm{m}$ by 5 to $20 \mu \mathrm{m}$ and is produced 2 to 3 days after mixing the two compatible mating types. The conjugation tube is usually sinuous and markedly narrower (Fig. 3 to 5) than regular hyphae. A hypha with clamp connections then grows out from the fusion product. Nuclear staining shows that the hyphal cell is dikaryotic (Fig. 6 and 7). Within 10 days, occasionally in 5 to 6 days, mature basidia appear in cultures (Fig. 12). Probasidia are thin walled and typically broader than the hyphae from which they originate. They develop
TABLE 2. All possible crosses of three Cryptococcus uniguttulatus isolates ${ }^{a}$

\begin{tabular}{rccc}
\hline Isolate & $\mathrm{Cu} 1$ & $\mathrm{Cu} 2$ & $\mathrm{Cu} 3$ \\
\hline $\mathrm{Cu} 1$ & - & + & + \\
$\mathrm{Cu} 2$ & + & - & - \\
$\mathrm{Cu} 3$ & + & - & - \\
\hline
\end{tabular}

${ }^{a}$ Symbols: +, basidiomycetous state produced, -, no reaction.

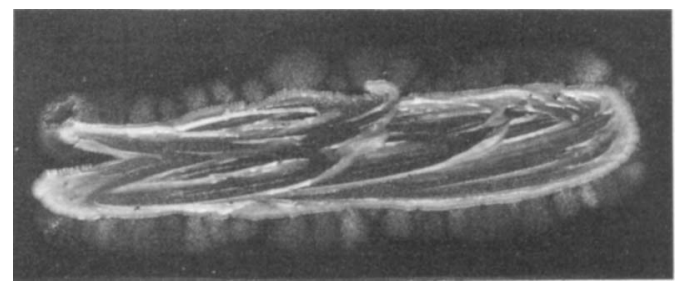

Fig. 1. Two-week-old mated culture of $\mathrm{Cu} 1 \times \mathrm{Cu} 2$ on hay agar plate. Magnification, $\times 1.5$.

TABLE 3. Results of backcrossing of 10 single basidiospore isolates ${ }^{a}$

\begin{tabular}{ccc}
\hline $\begin{array}{c}\text { Single basidio- } \\
\text { spore isolate }\end{array}$ & \multicolumn{2}{c}{ Back-crossing results } \\
\cline { 2 - 3 } & Cu1 $^{b}$ & Cu2 \\
\hline 1 & - & + \\
2 & + & + \\
3 & + & - \\
4 & + & - \\
5 & + & + \\
6 & + & + \\
7 & - & - \\
8 & + & - \\
9 & + & - \\
10 & + &
\end{tabular}

${ }^{a}$ Symbols: + , basidiomycetous state produced; -, no reaction.

${ }^{b}$ Parental strain.

mostly in a group of two to four but also develop singly on the sides of hyphae at the clamp or terminally on the hyphae (Fig. 8 and 9). Blastospores are occasionally produced laterally on the hyphae (Fig. 15). Pseudomycelium is not produced in a single culture nor in mated cultures. Basidia elongate, taper apically, and expand abruptly to produce a globose apex (Fig. 10). The basidiospores are budded put (Fig. 11) directly from the globose apex and are commonly six to eight in number. The basidiospores are arranged in a whorl (Fig. 12), which is characteristic of the genus Filobasidium. The spores are ovate to kidney shaped (Fig. 13). Although infrequent, narrow "haustorioid branches" (11) are produced typically from the clamp (Fig. 16). The detached basidiospores germinate into blastospores (Fig. 14). Conjugation was not observed when either mating type of $F$. uniguttulatum was mixed with tester 

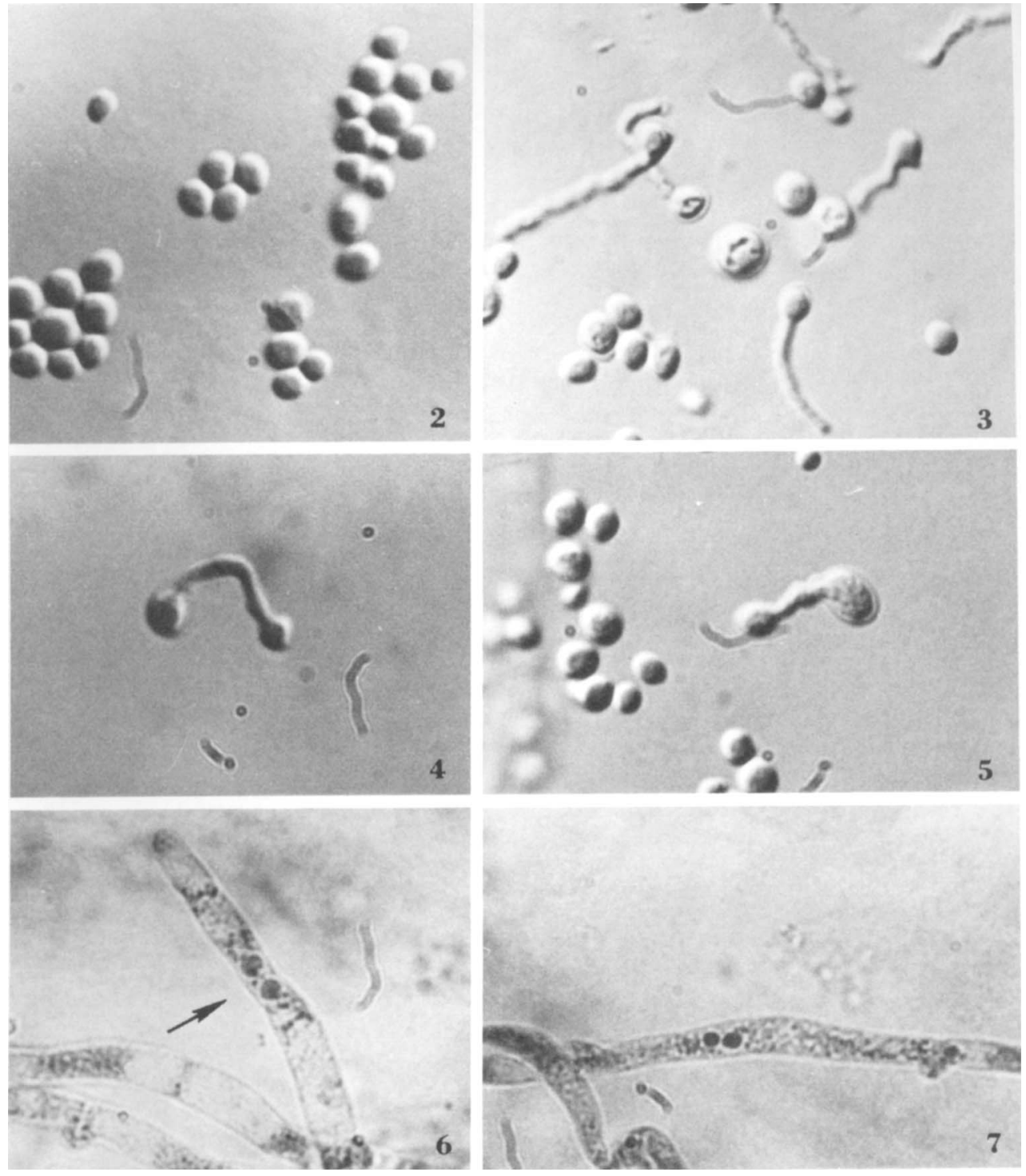

FIG. 2. Globose to ovate cells of a single culture Cu1. Magnification, $\times 1,400$.

Fig. 3. Formation of conjugation tube by the cells in a mixed culture of Cu1 and Cu2. Magnification, $\times 1,400$.

FIG. 4 and 5. Conjugated cells. Magnification, $\times 1,400$.

Fig. 6 and 7. Dikaryotic hyphae. Magnification, $\times 1,400$.

strains of $F$. floriforme or $F$. capsuligenum.

Physiological and morphological comparison of $F$. uniguttulatum with the other species of Filobasidium. Morphological and physiological characteristics of the three species of Filobasidium are compared in Tables 4 and 5, respectively. The most striking morphological difference lies in the size of basidial structures. The basidia and basidiospores of $F$. uniguttula- tum are the smallest followed by those of $F$. capsuligenum and $F$. floriforme in an increasing order.

Ability to ferment glucose separates the isolates of $F$. capsuligenum from $F$. uniguttulatum and $F$. floriforme (Table 5). The latter two species can be differentiated by the abilities to assimilate lactose, nitrate, cellobiose, and galactitol. 

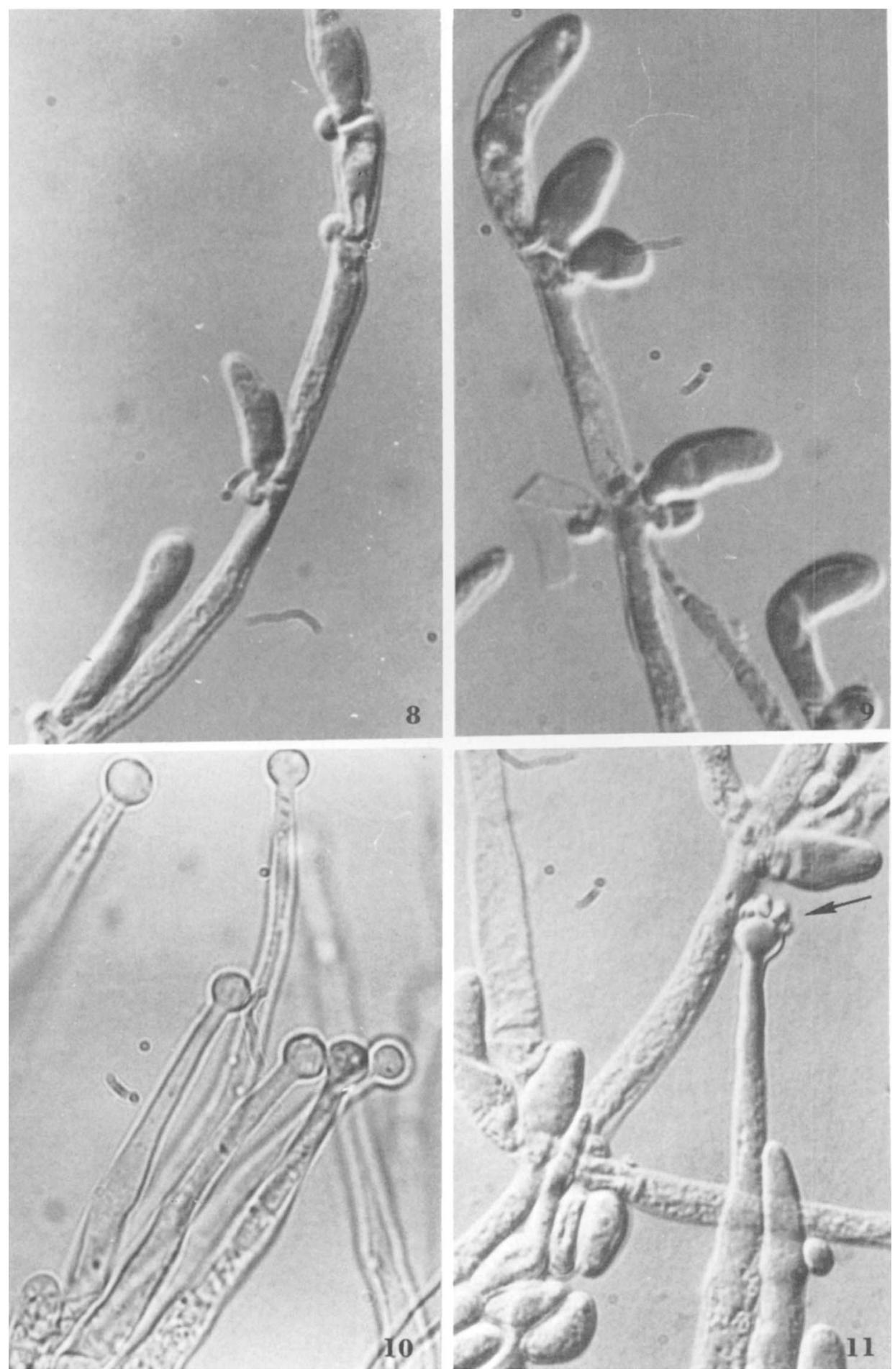

FIG. 8 and 9. Probasidia arising singly or in a group at the clamp or tip of the hypha. Magnification, $\times 1,400$.

Fig. 10. A group of basidia with globose apexes. Magnification, $\times 1,400$.

FIG. 11. Basidiospores budded out from the apex of a basidium (see arrow). Magnification, $\times 1,400$. 

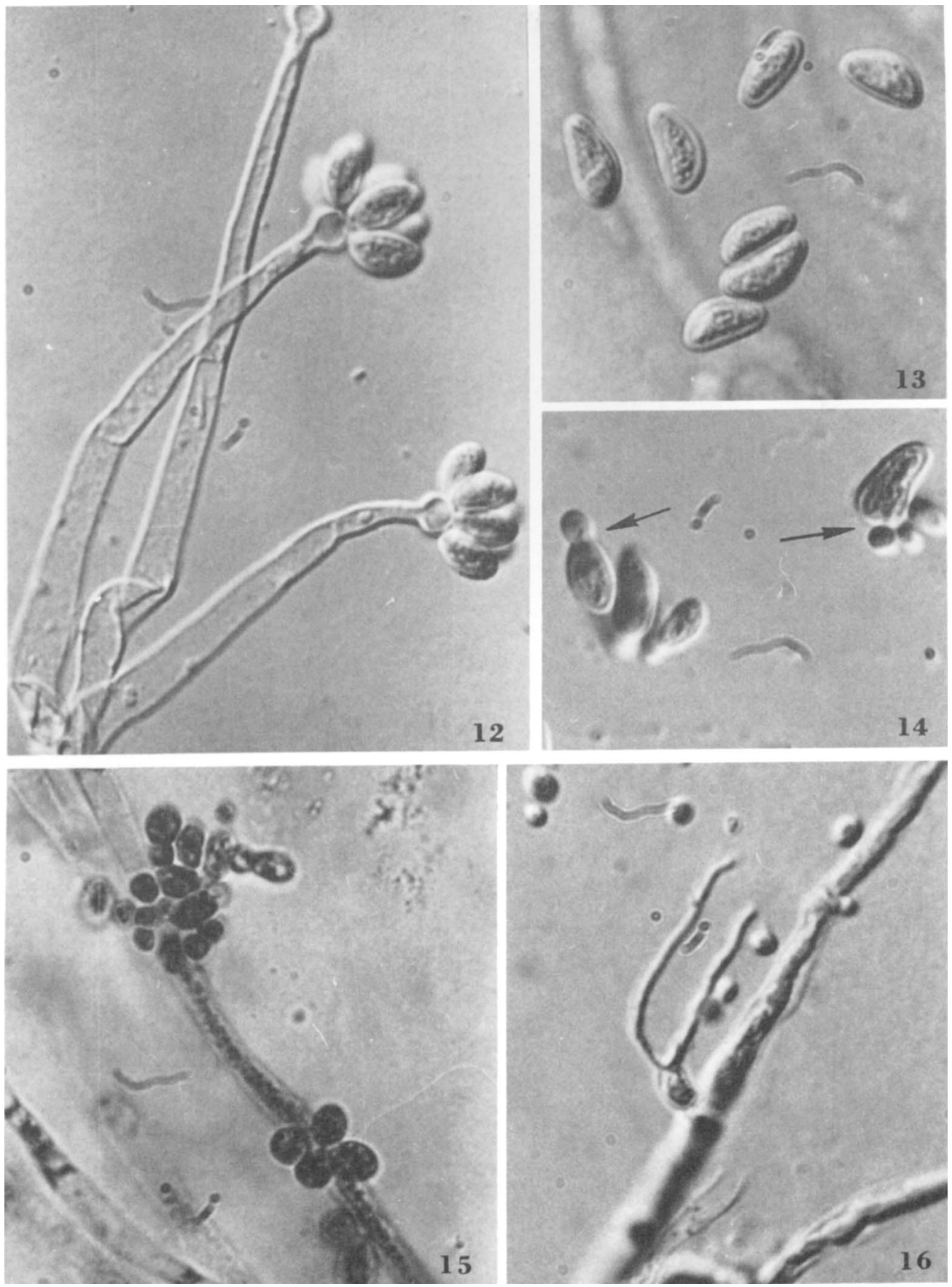

Fig. 12. Mature basidia with basidiospores. Magnification, $\times 1,400$.

FIG. 13. Ovate to kidney-shaped basidiospores. Magnification, $\times 1,400$.

FIg. 14. Basidiospores germinating into blastospores (see arrows). Magnification $\times 1,400$.

FIG. 15. Blastospores produced from a hypha. Magnification, $\times 1,400$.

Fig. 16. Haustorioid branches produced at the clamp on a hypha. Magnification, $\times 1,400$. 
TABLE 4. Morphological comparison of three Filobasidium species

\begin{tabular}{llll}
\hline \multicolumn{1}{c}{ Characteristic } & \multicolumn{1}{c}{$F$. uniguttulatum } & \multicolumn{1}{c}{$F$. floriforme } & \multicolumn{1}{c}{$F$. capsuligenum } \\
\hline Blastospores & Globose to oval & Long oval to elliptical & Elliptical elongate \\
Basidium & 4.0 to 6 by 30 to $90 \mu \mathrm{m}$ & 3.2 to 7 by 57 to $265 \mu \mathrm{m}$ & 3.0 to 6 by 70 to $140 \mu \mathrm{m}$ \\
Basidiospore & $\begin{array}{l}3 \text { to } 5 \text { by } 4 \text { to } 9 \mu \mathrm{g}, \text { reniform } \\
\text { to oval }\end{array}$ & $\begin{array}{c}6 \text { to } 9 \text { by } 10.5 \text { to } 16.5 \mu \mathrm{m}, \\
\text { elliptical to oval }\end{array}$ & $\begin{array}{c}4 \text { to } 6 \text { by } 9.5 \text { to } 13 \mu \mathrm{m} \text {, ellipt- } \\
\text { ical to fusiform }\end{array}$ \\
\hline
\end{tabular}

Table 5. Physiological differences between three species of Filobasidium

\begin{tabular}{|c|c|c|c|}
\hline Characteristic & F. uniguttulatum & $F$. floriforme & F. capsuligenum \\
\hline \multicolumn{4}{|l|}{ Fermentation } \\
\hline Glucose & - & - & + \\
\hline Maltose & - & - & - or latent \\
\hline \multicolumn{4}{|l|}{ Assimilation } \\
\hline Glucose & + & + & + \\
\hline Galactose & - or weak & + (latent) & + \\
\hline Sucrose & + & + & + \\
\hline Maltose & + & + & + \\
\hline Lactose & - & + & - \\
\hline L-Sorbose & - & + (latent) & + \\
\hline Cellobiose & - & + & + \\
\hline Raffinose & - or + & - & - \\
\hline Melibiose & - & - & - \\
\hline Melezitose & + & + & + \\
\hline L-Rhamnose & - or + (latent) & + & - \\
\hline L-Arabinose & - or + (latent) & + & - \\
\hline L-Malic acid & - & + & - \\
\hline Erythritol & - & - & - \\
\hline Galactitol & - & + & + or weak \\
\hline Inositol & + & + & + \\
\hline Creatinine & - & - & - \\
\hline Nitrate & - & + & - \\
\hline \multicolumn{4}{|l|}{ Growth temp } \\
\hline $30^{\circ} \mathrm{C}$ & + & + & + \\
\hline $37^{\circ} \mathrm{C}$ & - & weak & weak \\
\hline \multicolumn{4}{|l|}{ Enzymes } \\
\hline Urease & + & + & + \\
\hline Phenol oxidase & - & - & - \\
\hline
\end{tabular}

\section{DISCUSSION}

Cryptococcus uniguttulatus was first isolated from an infected human nail by Wolfram and Zach (19) and had been named as Eutorulopsis uniguttulata. Lodder and Kreger-Van $\mathrm{Rij}$ (9) redescribed this yeastlike fungus as Cryptococcus neoformans var. uniguttulatus on the basis of morphological and physiological similarities with $\mathrm{Cr}$. neoformans but with reduced capsule formation. In 1961, Kreger-Van Rij recognized some physiological characteristics which could be used as more reliable criteria than the degree of capsule formation (3) in differentiating the variety from the species. She found that isolates of $\mathrm{Cr}$. neoformans assimilated galactitol as sole carbon source and were able to grow at $37^{\circ} \mathrm{C}$ whereas the variety did not. Staib (15) found an additional difference between the species and the variety. $\mathrm{He}$ found that almost all isolates of $\mathrm{Cr}$. neoformans utilized creatinine as a sole nitrogen source whereas the isolates of the variety were unable to assimilate creatinine. On the basis of these dissimilarities, Staib (15) recommended that the variety be raised to the rank of species. In 1970, Phaff and Fell concurred with this view and created the species status for the variety, as Cr. uniguttulatus (Wolfram and Zach) Phaff and Fell (12).

Discovery of $F$. uniguttulatum unequivocally supports this decision. In fact it is clear that $\mathrm{Cr}$. uniguttulatus is phylogenetically closer to $\mathrm{Cr}$. albidus or Candida capsuligena than to $\mathrm{Cr}$. neoformans. The sexual states of $\mathrm{Cr}$. neoformans are described in the separate genus Filobasidiella $(5,7)$ under the same family Filobasidiaceae (11). Mechanism of basidiospore formation and size of basidial structures in the species of Filobasidiella (6) are entirely different from those of Filobasidium. In Filobasidiella, 
basidiospores are produced in chains by basipetal repetitious budding.

The mating reactions among the original three strains or the mating reactions between $F_{1}$ progeny and the parental strains of $F$. uniguttulatum reveal only that the species is heterothallic. Further analyses are underway to determine the compatibility mechanism in this fungus.

\section{ACKNOWLEDGMENTS}

I am grateful to W. B. Hill and F. A. McNey, of our section, for their technical assistance.

\section{REPRINT REQUESTS}

Address reprint requests to: Dr. K. J. Kwon-Chung, Laboratory of Clinical Investigation, National Institute of Allergy and Infectious Diseases, National Institutes of Health, Bethesda, Md. 20014.

\section{LITERATURE CITED}

1. Christensen, W. B. 1946. Urea decomposition as a means of differentiating Proteus and Paracolon cultures from each other and from Salmonella and Shigella types. J. Bacteriol. 52:461-466.

2. Fell, J. W., A. Statzell, I. L. Hunter, and H. J. Phaff. 1969. Leucosporidium gen. n., the heterobasidiomycetous stage of several yeasts of the genus Candida. Antonie van Leeuwenhoek J. Microbiol. Serol. 35:433-462.

3. Kreger-van Rij, N. J. W. 1961. Taxonomy of Cryptococcus neoformans and its variety uniguttulatus. Antonie van Leeuwenhoek J. Microbiol. Serol. 27:59-64.

4. Kwon-Chung, K. J. 1969. Coccidioides immitis: cytological study on the formation of the arthrospores. Can. J. Genet. Cytol. 11:43-53.

5. Kwon-Chung, K. J. 1975. A new genus Filobasidiella, the perfect state of Cryptococcus neoformans. Mycologia 67:1197-1200.
6. Kwon-Chung, K. J. 1976. Morphogenesis of Filobasidiella neoformans, the sexual state of Cryptococcus neoformans. Mycologia 68:821-833.

7. Kwon-Chung, K. J. 1976. A new species of Filobasidiella, the sexual state of Cryptococcus neoformans $B$ and C serotypes. Mycologia 68:942-946.

8. Lodder, J. 1970. The yeasts, a taxonomic study. North Holland Publishing Co., Amsterdam.

9. Lodder, J., and N. J. W. Kreger-van Rij. 1952. The yeasts, a taxonomic study. North Holland Publishing Co., Amsterdam.

10. Moore, R. T., and N. J. W. Kreger-Van Rij. 1972. Ultrastructure of Filobasidium Olive. Can. J. Microbiol. 18:1949-1951.

11. Olive, L. S. 1968. An unusual new heterobasidiomycete with Tilletia-like basidia. J. Elisha Mitchell Sci. Soc. 84:261-266.

12. Phaff, H. J., and J. W. Fell. 1970. Cryptococcus Kützing emend. Phaff et Spencer, p. 1088-1145. In J. Lodder, (ed). The yeasts, 2nd ed. North Holland Publishing Co., Amsterdam.

13. Raper, K. B., and D. I. Fennell. 1965. The genus Aspergillus. Williams and Wilkins Co., Baltimore.

14. Rodrigues de Miranda, L. 1972. Filobasidium capsuligenum nov. comb. Antonie van Leeuwenhoek J. Microbiol. Serol. 38:91-99.

15. Staib, F. 1963. Zur Kreatinin-Kreatin-Assimilation in der Hefepilzdiagnostik. Zentralbl. Bakteriol. Parasitenkd. Infektionskr. Hyg. Abt. 1 Orig. 191:429-432.

16. Staib, F., and H. P. R. Seeliger. 1966. A new selective medium for the isolation of $C$. neoformans from soil and fecal matter. Ann. Inst. Pasteur Paris 110:792793.

17. Van Uden, N., and H. Buckley, 1970. Candida Berkhout, p. 893-1087. In J. Lodder, (ed.), The yeasts, 2nd ed. North Holland Publishing Co., Amsterdam.

18. Van der Walt, J. P. 1970. Criteria and methods used in classification, p. 34-113. In J. Lodder, (ed.), The yeasts, 2nd ed. North Holland Publishing Co., Amsterdam.

19. Wolfram, S., and F. Zach. 1934. Über durch niedere Pilze verursachte Nagelerkrankungen beim Menschem. Arch Dermatol. Syphilis 170:681-694. 